\title{
A Web-Based Photo-Alteration Intervention to Promote Sleep: Randomized Controlled Trial
}

Isabel Perucho $^{1^{*}}$, BA; Kamalakannan M Vijayakumar ${ }^{*}$, BA; Sean N Talamas ${ }^{2}, \mathrm{PhD}$; Michael Wei-Liang Chee ${ }^{3}$, MBBS; David I Perrett ${ }^{4}, \mathrm{PhD}$; Jean C J Liu ${ }^{1,3}, \mathrm{PhD}$

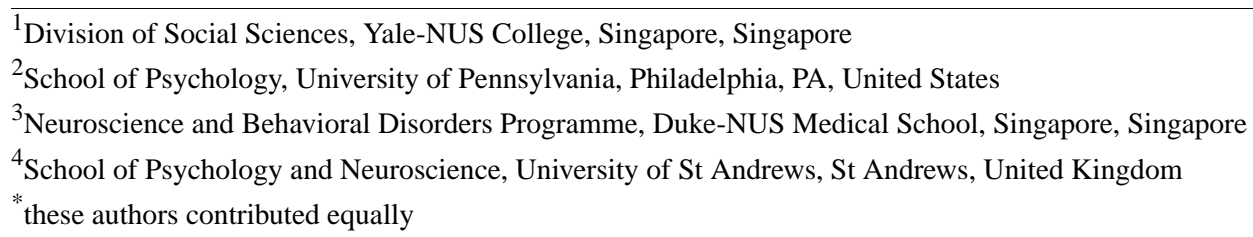

Corresponding Author:

Jean C J Liu, PhD

Division of Social Sciences

Yale-NUS College

16 College Ave West \#02-221

Singapore, 138527

Singapore

Phone: 6566013694

Email: jeanliu@yale-nus.edu.sg

\section{Abstract}

Background: Receiving insufficient sleep has wide-ranging consequences for health and well-being. Although educational programs have been developed to promote sleep, these have had limited success in extending sleep duration. To address this gap, we developed a Web-based program emphasizing how physical appearances change with varying amounts of sleep.

Objective: The aims of this study were to evaluate (1) whether participants can detect changes in appearances as a function of sleep and (2) whether this intervention can alter habitual sleep patterns.

Methods: We conducted a 5-week, parallel-group, randomized controlled trial among 70 habitual short sleepers (healthy adults who reported having $<7$ hours of sleep routinely). Upon study enrollment, participants were randomly assigned (1:1) to receive either standard information or an appearance-based intervention. Both groups received educational materials about sleep, but those in the appearance group also viewed a website containing digitally edited photographs that showed how they would look with varying amounts of sleep. As the outcome variables, sleep duration was monitored objectively via actigraphy (at baseline and at postintervention weeks 1 and 4), and participants completed a measure of sleep hygiene (at baseline and at postintervention weeks 2, 4, and 5). For each outcome, we ran intention-to-treat analyses using linear mixed-effects models.

Results: In total, 35 participants were assigned to each group. Validating the intervention, participants in the appearance group (1) were able to identify what they looked like at baseline and (2) judged that they would look more attractive with a longer sleep duration $\left(t_{26}=10.35, P<.001\right)$. In turn, this translated to changes in sleep hygiene. Whereas participants in the appearance group showed improvements following the intervention $\left(F_{1,107.99}=9.05, P=.003\right)$, those in the information group did not $\left(F_{1,84.7}=0.19\right.$, $P=$.66). Finally, there was no significant effect of group nor interaction of group and time on actigraphy-measured sleep duration (smallest $P=.26$ ).

Conclusions: Our findings suggest that an appearance-based intervention, while not sufficient as a stand-alone, could have an adjunctive role in sleep promotion.

Trial Registration: ClinicalTrials.gov NCT02491138; https://clinicaltrials.gov/ct2/show/study/NCT02491138.

(J Med Internet Res 2019;21(9):e12500) doi: 10.2196/12500

\section{KEYWORDS}

sleep; public health; physical appearance; outward appearance 


\section{Introduction}

\section{Background}

Sleep is often described as 1 of 3 pillars of health, ranked alongside nutrition and exercise as modifiable targets of well-being. Underscoring this point, a large body of evidence suggests that the habitual curtailment of sleep increases the risk of obesity [1-3], coronary heart disease [4], stroke [4], and all-cause mortality [5,6]. Despite the centrality of sleep, 1 in 3 adults routinely obtain less than the recommended 7 hours of sleep for healthy adults [7,8]. Accordingly, the US Department of Health and Human Services has outlined a nation-wide goal to reduce the number of habitual short sleepers over a 10-year period [9].

Despite this goal, sleep promotion campaigns have met with limited success. In a typical program, participants are briefed about the mechanics of sleep (eg, sleep architecture), the importance of sleep, and sleep hygiene-lifestyle habits that facilitate sleep (eg, abstaining from excessive caffeine intake during the night [10]) [11-13]. Delivery of these programs range from simply providing a pamphlet [14] to hosting multiple sessions (eg, 8 sessions over 5 weeks [15]). Although sleep promotion programs may raise awareness, they fare poorly in changing actual behavior [11,12]. Even among programs that have reported increased sleep duration, gains have been short-lived, observed only immediately after the intervention [13].

Reviewing this evidence, Cassoff et al suggested that merely providing information may not be sufficient and that greater emphasis should be placed on motivational aspects of modifying sleep [12]. This concurs with surveys suggesting that-despite knowing the importance of sleep-many forsake it for immediate priorities such as meeting deadlines [16,17]. That is, they engage in temporal discounting, weighting short-term rewards (eg, completing one's assignment) over long-term outcomes (eg, reduced risk of all-cause mortality) [18,19]. This aligns with research in other health domains (eg, appetite regulation), where interventions emphasizing short-term gains (eg, financial incentives for weight loss or exercise) were found to encourage healthy behaviors [20,21]. Correspondingly, one way to motivate better sleep patterns may be to highlight short-term outcomes [22,23]-the proximate incentives of increased sleep duration or the proximate costs of sleep curtailment. To this end, we evaluated a sleep promotion program emphasizing 1 immediate outcome-how physical appearances change as a function of sleep duration.

\section{Developing an Appearance-Based Intervention for Sleep Promotion}

Physical appearance is highly valued across cultures [24], and the desire to be attractive has motivated healthy behaviors in both men and women [25]. For example, in the prevention of skin cancers, showing participants how they would look with continued sun exposure has been found repeatedly to increase sun-protection behaviors and reduce indoor tanning frequency [25]. In smoking cessation campaigns, showing the photoaging effects of tobacco has likewise increased readiness to change and actual quit attempts [26,27]. Finally, a recent study found that when participants were shown how their skin color would vary as a function of nutrition, their intake of fruit and vegetable consumption increased, with effects lasting for 10 weeks postintervention [28].

In the context of sleep, physical appearances track sleep duration within a short time window (eg, after 31 hours of total sleep deprivation [29,30] or following 2 nights with 4 hours of sleep opportunity [31]). Relative to adequate sleep ( $\geq 7$ hours), sleep loss results in hanging eyelids, redder and swollen eyes, darker eye circles, wrinkles and fine lines around the eyes, a droopy mouth, and poorer skin quality (eg, worsened skin hydration and elasticity and paler skin) [30,32]. In turn, these alterations are associated with looking sadder [30], less intelligent [33], less attractive [29], less healthy [29], and less desirable as a social companion [31]. Given the immediate and salient nature of these changes, physical appearances could serve as a motivator to overcome temporal discounting. Accordingly, we developed a novel Web-based intervention to capitalize on these changes.

To summarize, we sought in this study to highlight the immediate impact of sleep loss on physical appearances. Drawing from other health domains (sun protection, smoking cessation, and diet), we hypothesized that the appearance-based intervention would augment a standard informational campaign in increasing sleep duration. Furthermore, because poor sleep hygiene predisposes a person to impaired nocturnal sleep and is targeted in sleep education programs [10,11], we tracked changes in sleep hygiene habits as an additional indicator of behavioral change [34].

\section{Methods}

\section{Study Design}

This study involved a randomized controlled open-label trial with 2 arms: a standard information intervention and an appearance-based intervention. The trial design and outcomes were preregistered in ClinicalTrials.gov (NCT02491138) and remained unchanged throughout the study. All procedures were approved by the National University of Singapore's Institutional Review Board (A-15-083).

\section{Participants}

A total of 70 young adults were recruited from the National University of Singapore between July 2015 and December 2016. Participants responded to advertisements within the university and registered their interest via an online website. Thereafter, they were included if they were (1) aged between 18 and 24 years; (2) had no history of psychiatric, sleep, neurological, or medical disorders (including insomnia); (3) had no history of substance abuse; and (4) reported habitual short sleep (as defined by current sleep guidelines: sleep duration of $<7$ hours [8]).

Following written informed consent (see Multimedia Appendix 1), participants were randomized to the 2 groups with a 1:1 allocation. The allocation sequence was prepared by the study coordinator before trial commencement and involved a computer-generated list of random numbers. Both participants and research assistants became aware of the allocation on the 
intervention day; however, research staff involved in data entry and data cleaning were blinded to participant grouping. Participants were not told what the intervention of interest was.

\section{Procedures}

As a baseline measure, participants completed 1 week of sleep monitoring where they kept a sleep diary [35] and wore a wrist actigraph on the nondominant hand (Actiwatch; Philips Respironics, Inc, Pittsburgh, PA). Activity was recorded in epochs of $2 \mathrm{~min}$, and actigraphy measures were calculated using Actiware 6.0.5 (Philips Respironics, Inc, Pittsburgh, PA) after photosensor data and sleep diaries were reviewed.

During the baseline phase, participants also attended the laboratory for a face-to-face visit where they completed the Sleep Hygiene scale [36]. This scale involved 19 items assessing the number of days each week participants engaged in poor sleep hygiene practices (eg, slept in a room that was too bright; worried, planned, or thought about important matters in bed). The 19 items were then averaged to form a composite score, with higher scores indicating poorer sleep hygiene (Cronbach $\alpha=.72$ ). As this component is targeted in typical sleep education programs, any improvements from baseline would represent a preliminary step in behavioral change.

As additional baseline measures, participants were also characterized with 2 questionnaires assessing sleep quality and attitudes: (1) the Dysfunctional Beliefs and Attitudes about
Sleep scale (DBAS-16) [37], a 16-item measure of insomnia-related cognition (Cronbach $\alpha=.87$ ); and (2) the Pittsburgh Sleep Quality Index (PSQI) [38], a 19-item measure of sleep quality over the past week (Cronbach $\alpha=.52)$. Finally, facial photographs were obtained from all participants (regardless of their intervention group).

For the photoshoot, 3 facial photographs were taken in a standardized room under constant lighting (resolution: $3648 \times$ 5472 pixels, Canon Powershot G7X; Canon Inc, Tokyo, Japan). Before taking photographs, participants removed any spectacles and jewelry, combed their hair backwards, were clean shaven, and applied a facial wipe. They were then instructed to look into the camera with a neutral expression, with photographs taken at a fixed distance from the camera.

After the baseline phase (week 0), participants visited the laboratory individually where they received either the information or appearance-based intervention. Following this visit, participants repeated the sleep hygiene scale (weeks 2, 4, and 5) and completed 2 weeks of wrist actigraphy (weeks 1 and 4). Finally, they repeated the DBAS-16 and PSQI questionnaires (in weeks 2, 4, and 5). Upon study completion, participants were reimbursed SGD \$50. All study visits took place at the behavioral laboratories of Yale-NUS College in Singapore, with procedures and measures administered in English - the lingua franca of the country (see Figure 1 for a schematic of study procedures).

Figure 1. Schematic of study procedures. All participants received the intervention in week 1 and had their sleep patterns monitored through actigraphy in weeks 0 (baseline), 1, and 4. The sleep hygiene questionnaire was also administered in weeks 0 (baseline), 2, 4, and 5 (marked in the figure with an "x").

\begin{tabular}{|c|c|c|c|c|c|c|}
\hline \multirow[b]{2}{*}{$x$} & \multicolumn{2}{|c|}{ Intervention } & \multirow[b]{2}{*}{$x$} & & \multirow{2}{*}{\multicolumn{2}{|c|}{$x$}} \\
\hline & & 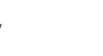 & & & & \\
\hline & aphy & Actic & & & & Actigraphy \\
\hline & & 1 & 2 & 3 & 4 & \\
\hline
\end{tabular}

\section{Interventions}

\section{Standard Information}

In the standard information group, participants were shown a slideshow containing materials based on public health websites $[39,40]$ and previous sleep education studies [11-13]. A trained research assistant walked participants through the slide contents, introducing them to: the functions of sleep, the consequences of sleep curtailment, behavioral signs of insufficient sleep, and sleep hygiene principles to promote sleep (eg, noise management in the sleeping environment). Participants were then given a take-home pamphlet containing this same information and were not given the opportunity to ask questions. Each session was conducted individually and spanned approximately $20 \mathrm{~min}$.

\section{Appearance-Based Intervention}

In the appearance group, transformed versions of baseline photographs were presented through an internet platform to show how appearances would change with sleep duration. Sleep-related changes were ascertained from an earlier study where 25 healthy adults were photographed following rested wakefulness (7-9 hours of sleep) and following 2 nights of sleep restriction (where they were given 4 hours of sleep opportunity) [31]. Using Psychomorph 6 [41] — a free software for photo transformation-these faces were blended to create 2 masks for each state (rested vs sleep restricted). Transformations were then applied by first delineating participants' photographs with 175 feature points aligned based on interpupillary distance. Using the masks, participants' photographs were transformed to create a continuum of 13 images, with Image 0 showing what 
participants would look like if they had insufficient sleep (300\% of the difference between the rested and sleep restricted masks; Figure 2). This progressed incrementally with Image 6 as the original image, and Image 12 showing what participants would look like if they received more sleep $(300 \%$ of the difference in the opposite direction; Figure 2).

Figure 2. In the appearance-based intervention, participants were shown what they would look like as a function of varying sleep duration. (A) Each participant's face was digitally edited to show them their sleep restricted (left image) and well-rested selves (right image). (B) A continuum of 13 images was created and presented to participants through an online website.

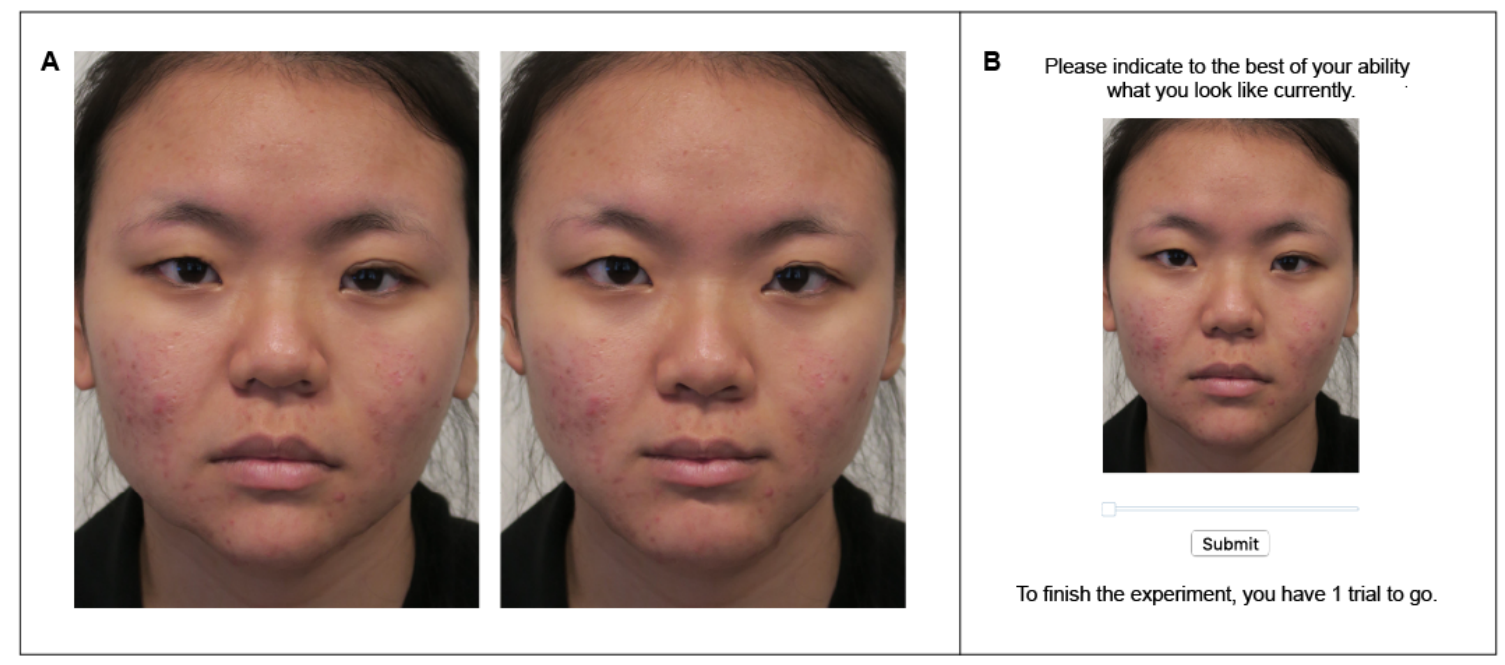

During the intervention visit, participants were shown the same slideshow presentation as the information group. However, after hearing about the signs of insufficient sleep, they were shown a website where the 13 transformed images were presented on a continuum, with a sliding scale to manipulate appearance changes as a function of sleep duration (Figure 2). Participants scrolled through the website in a self-paced manner and were asked to (1) identify what they looked like at present and (2) to adjust the scale to select their most attractive self. Upon making their choices, participants were again presented with Images 0 (their sleep-restricted selves) and 12 (their well-rested selves). Referring to these images, the trained research assistant highlighted how sleep curtailment affected their appearances (eg, hanging eyelids and droopy mouth), and how that could be perceived by others (eg, as less attractive). Thereafter, participants were reminded of the costs many incur for physical attractiveness (eg, paying a gym membership for \$100/month), relative to the benefits accrued from extending sleep duration. Finally, participants were presented information about sleep hygiene practices and were given a take-home pamphlet (similar to the information group). Each session was conducted individually and spanned approximately $30 \mathrm{~min}$, with neither an invitation for participants to ask questions nor further access to the website (following the intervention).

\section{Statistical Analysis}

For the primary outcome measures (actigraphy-measured sleep duration and sleep hygiene scores), we ran intention-to-treat analyses using linear mixed-effects models, with parameters estimated using maximum likelihood estimation for a first-order autoregressive covariance structure. This examined individual change in each measure over time, with group (information or appearance), time (sleep duration: weeks 0,2 , 4, and 5; sleep hygiene: 0,1 , and 4 ), and the group $\times$ time interaction entered as fixed effects. Random intercepts accounted for correlated data due to repeated measures. Although the reliability of the PSQI was low in our sample (Cronbach $\alpha=.52)$, baseline scores differed between the groups and were entered as covariates [42]; however, the conclusions did not change with and without this adjustment. Finally, for sleep duration, separate models were run for weekdays and for weekends to account for differences in sleep patterns across the week [43].

For the secondary outcome measures (global PSQI and DBAS-16 scores), we ran linear mixed-effects models identical to those used for the primary outcome measures, except that the model with global PSQI scores did not include covariates.

All analyses were conducted using SPSS 25 (IBM Corp, Armonk, NY) and R 3.4.0 (R Core Team, Vienna, Austria), with the type 1 decision-wise error rate controlled at $\alpha=.05$. Power calculations for the main intention-to-treat analyses showed that there was statistical power at the recommended .80 level to detect a medium effect size (computed through simulations, based on a meta-analysis evaluating appearance-based interventions for sun protection behaviors [25]). Accordingly, data collection was scheduled to cease when 70 participants had been recruited.

\section{Results}

\section{Participant Characterstics}

Full details on participant flow are shown in Figure 3. At baseline, actigraphy monitoring showed that participants slept an average of 5.9 hours on weekdays (SD 0.90 hours) and 6.4 hours on weekends (SD 1.32 hours). There were no significant group differences in baseline: gender, ethnicity, age, DBAS, sleep hygiene scores, and actigraphy-measured sleep variables 
(Tables 1 and 2). However, baseline global PSQI differed between groups and was included as a covariate.

Figure 3. Consolidated Standards of Reporting Trials flow diagram.

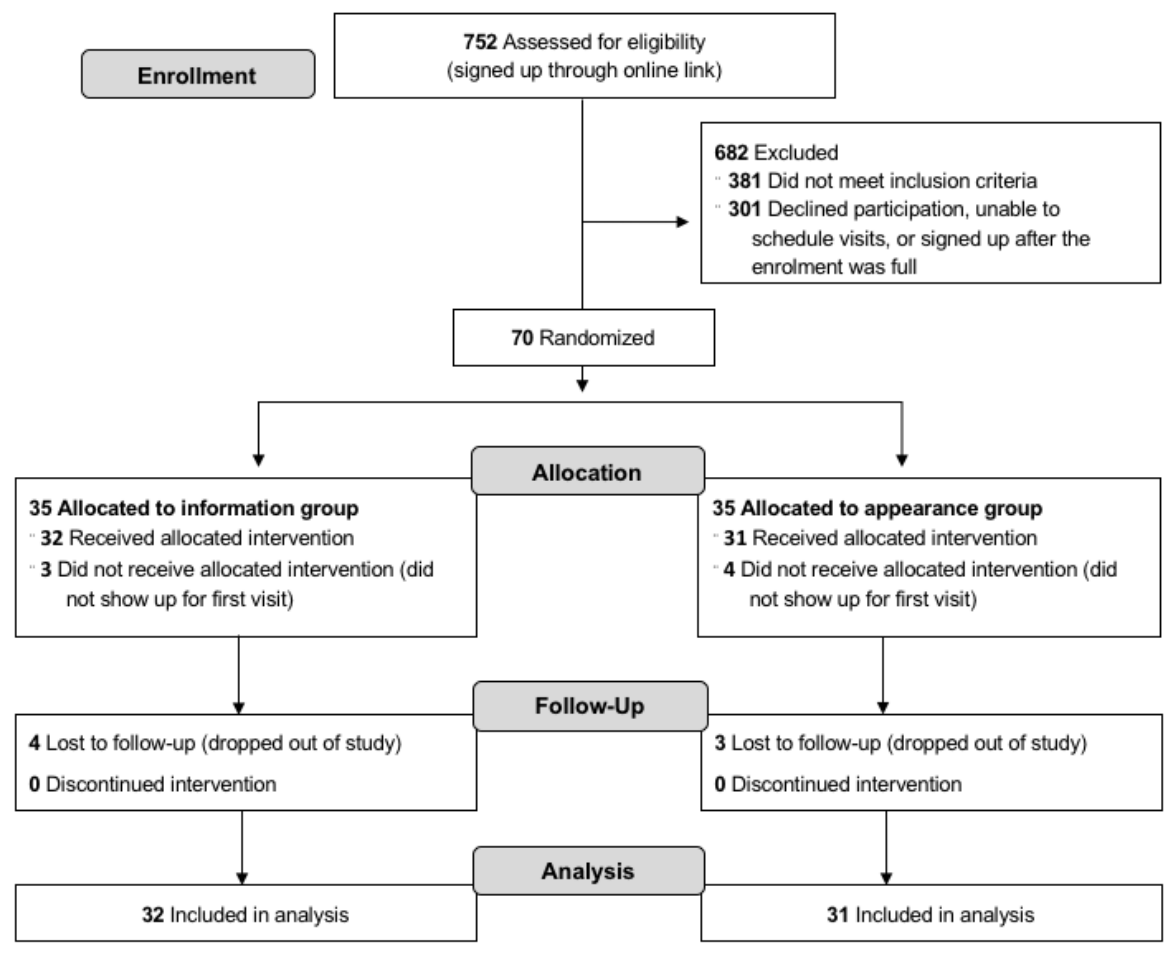

Table 1. Baseline characteristics of participants in the information and appearance groups.

\begin{tabular}{lllll}
\hline Characteristics & Information $(\mathrm{n}=32), \mathrm{n}(\%)$ & Appearance $(\mathrm{n}=31), \mathrm{n}(\%)$ & Chi-square $(d f)$ & $P$ value \\
\hline Gender & $25(78)$ & $18(58)$ & $2.92(1)$ & .09 \\
$\quad$ Female & & & $7.83(8)$ & .45 \\
Ethnicity & $23(72)$ & $22(71)$ & $-{ }^{\mathrm{a}}$ & - \\
$\quad$ Chinese & $4(12)$ & $7(22)$ & - & - \\
$\quad$ Indian & $5(16)$ & $2(6)$ & - & - \\
Others & & &
\end{tabular}

${ }^{\mathrm{a}}$ Not applicable. 
Table 2. Baseline characteristics of participants by sleep score and actigraphy metrics.

\begin{tabular}{|c|c|c|c|c|}
\hline Characteristics & $\begin{array}{l}\text { Information }(n=32) \text {, } \\
\text { mean }(S D)\end{array}$ & $\begin{array}{l}\text { Appearance }(n=31) \text {, } \\
\text { mean }(S D)\end{array}$ & $t$ test & $P$ value \\
\hline Age (years) & $20.66(1.91)$ & $22.13(2.14)$ & $-0.93(61)$ & .36 \\
\hline \multicolumn{5}{|l|}{ Mean sleep questionnaire scores } \\
\hline Pittsburgh Sleep Quality Index (global score) & $10.72(2.70)$ & $9.57(1.65)$ & $1.99(57)$ & .05 \\
\hline Dysfunctional Beliefs and Attitudes about Sleep & $4.42(1.32)$ & $4.67(1.44)$ & $-0.71(61)$ & .48 \\
\hline Sleep Hygiene Score & $2.61(0.74)$ & $2.52(0.65)$ & $0.51(61)$ & .61 \\
\hline \multicolumn{5}{|l|}{ Mean actigraphy metrics (averaged across the week) } \\
\hline Bed time (hours:min) & $2: 18(1: 02)$ & $1: 57(1: 14)$ & $1.19(56)$ & .24 \\
\hline Wake time (hours:min) & $8: 57(1: 05)$ & $8: 47(1: 12)$ & $0.57(56)$ & .57 \\
\hline Weekday sleep duration (hours:min) & $5: 55(0: 52)$ & $5: 54(0: 56)$ & $0.04(56)$ & .97 \\
\hline Weekend sleep duration (hours:min) & $6: 07(1: 18)$ & $6: 42(1: 18)$ & $-1.71(55)$ & .09 \\
\hline Sleep latency (mins) & $12.77(8.01)$ & $14.00(8.81)$ & $0.55(56)$ & .58 \\
\hline Wake after sleep onset (mins) & $30.78(17.24)$ & $29.99(17.36)$ & $0.17(56)$ & .86 \\
\hline Sleep efficiency $(\%)$ & $85.16(5.14)$ & $86.12(5.51)$ & $-0.69(56)$ & .49 \\
\hline
\end{tabular}

\section{Validating the Appearance-Based Intervention}

When participants in the appearance group were asked to select what they looked like, they identified Image 6.81 on average (SD 3.32). A one-sample $t$ test found no evidence that this differed from the actual baseline image (Image 6; $t_{26}=1.28$, $P=.21,95 \% \mathrm{CI}$ for the mean difference: -0.50 to 2.13 ); in other words, participants correctly identified their current appearances.
On the other hand, participants selected Image 9.96 (SD 1.99) as the most attractive version of themselves. This differed from the baseline by an average increment of 3.96 steps $(95 \% \mathrm{CI}$ for the mean difference: $3.18-4.75 ; t_{26}=10.35, P<.001 ; d=1.99$ ). Together, the pattern of website clicks validates the appearance-based intervention, showing how participants (1) were sensitive to the photo transformations and (2) judged that they would look more attractive after a longer sleep duration (Figure 4).

Figure 4. Participants viewed a continuum of 13 images transformed to show what they would look like with less or more sleep. When asked to identify their current selves, participants accurately identified an image close to the baseline (Image 6). They further judged that they would look more attractive following extended sleep. (Along the continuum, dots represent the mean images participants chose, and horizontal lines depict $95 \%$ CIs for the mean.).

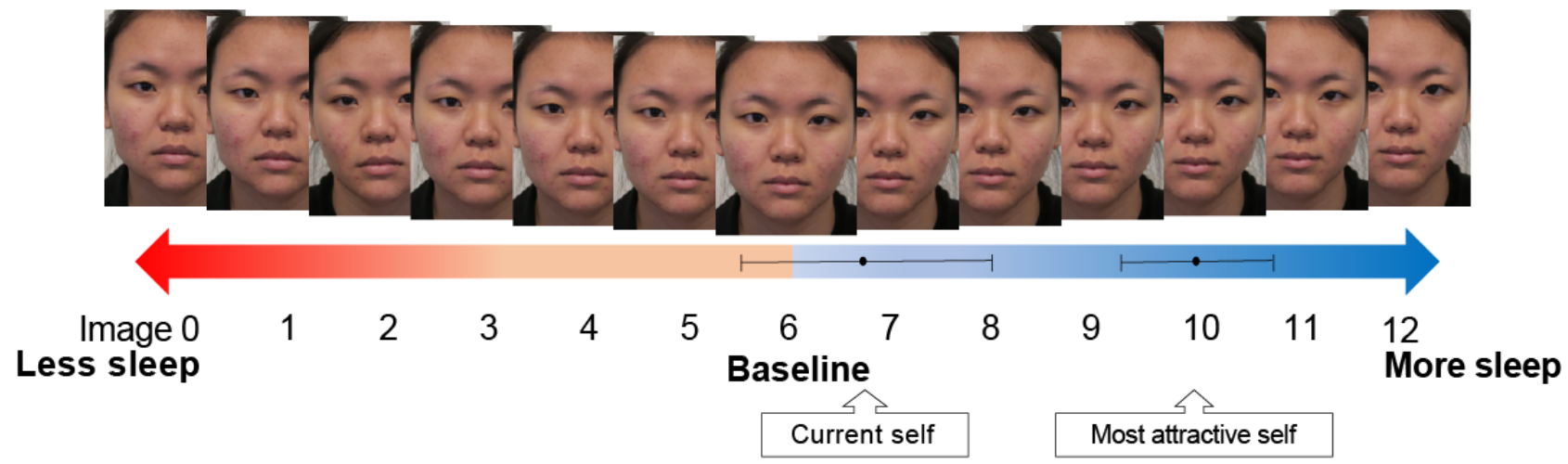

\section{Effect of the Appearance-Based Intervention: Sleep Hygiene}

Compared with a standard information program, the appearance-based approach was more successful in changing behaviors that could result in better sleep. Namely, on the sleep hygiene measure, participants in the appearance group showed improved sleep hygiene after the intervention (effect of time: $\left.F_{1,107.99}=9.05, P=.003\right)$, whereas those in the information group did not show significant changes (effect of time: $F_{1,84.7}=0.19$, $P=.66$; Figure 5). Comparing across time points, no group differences were observed at baseline or at week 2 postintervention (smallest $P=.27$ ). However, the appearance group reported better sleep hygiene than the information group in week $4\left(F_{1,38}=6.14, P=.02 ; 95 \% \mathrm{CI}:-0.78\right.$ to $\left.-0.08 ; \eta_{\mathrm{p}}{ }^{2}=0.14\right)$ and week $5\left(F_{1,49}=6.23, P=.02 ; 95 \%\right.$ CI: -0.68 to -0.07 ; $\left.\eta_{\mathrm{p}}{ }^{2}=0.11\right)$. 
Figure 5. Mean sleep hygiene scores for participants in the information and appearance groups, plotted as a function of time (baseline and postintervention weeks 2, 4, and 5). A higher score corresponds to poorer sleep hygiene, and vertical lines represent 1 standard error of the mean.

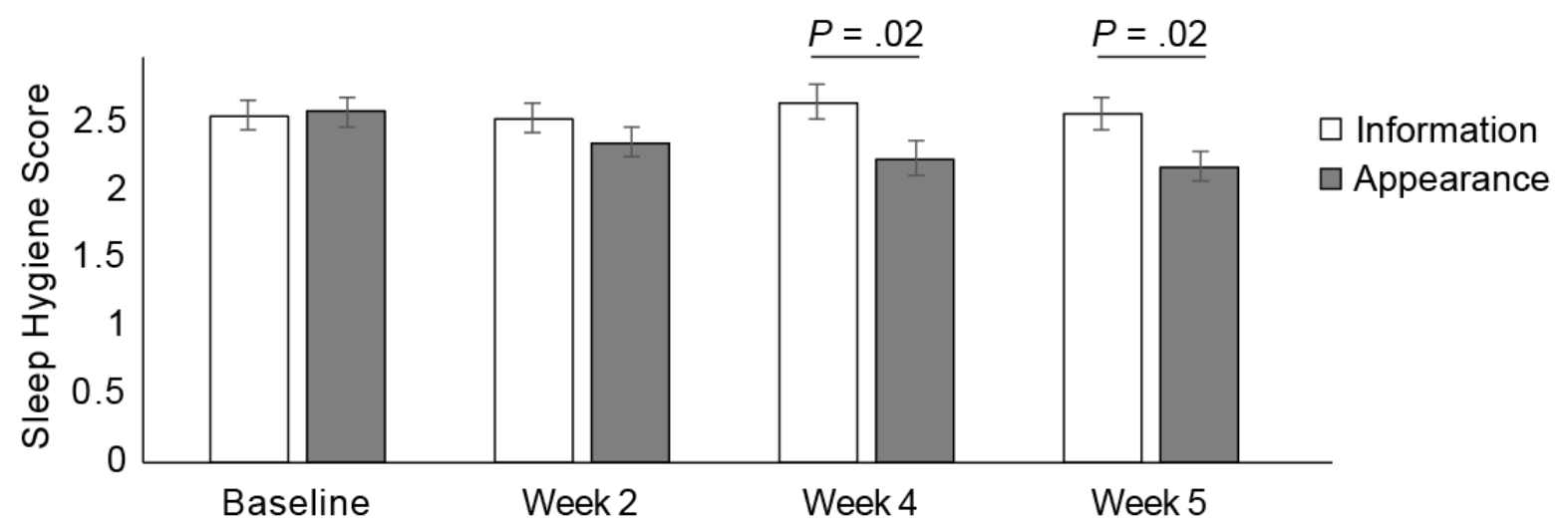

\section{Effect of the Appearance-Based Intervention: Actigraphy-Measured Sleep Duration}

As shown in Figure 6, there was neither any significant effect of time on weekday sleep duration $\left(F_{2,96.71}=0.19, P=.83\right)$ nor a significant interaction between time and group $\left(F_{2,96.71}=1.38\right.$, $P=$.26). For weekend sleep duration, there was again no significant effect of time $\left(F_{2,103.77}=0.50\right)$, nor a time $\times$ group interaction $\left(F_{2,103.77}=0.16, P=.85\right.$; Figure 5). In Multimedia Appendix 2, Table $\mathrm{S} 1$ shows adjusted means for the primary mixed-effects analyses, and Multimedia Appendix 2, Table S2 shows the corresponding unadjusted means. Finally, Multimedia Appendix 2, Table S3 shows how sleep quality and insomnia-related cognition remained stable throughout the trial (smallest $P$ for time or the time-group interaction=.48).

Figure 6. Mean sleep duration of participants in the information and appearance groups, plotted as a function of time (baseline and postintervention weeks 1 and 4 ). Vertical lines represent 1 standard error of the mean.

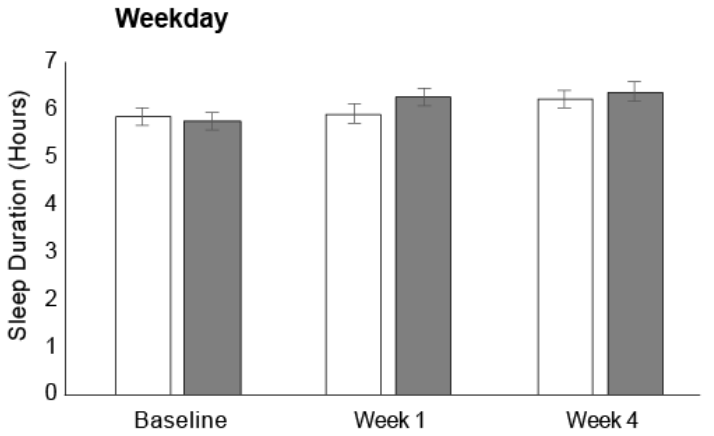

\section{Discussion}

\section{Principal Findings}

In this study, we developed a Web-based appearance-based intervention to promote sleep among habitual short sleepers. As a proof of concept, we first confirmed that participants (1) were sensitive to appearance changes and (2) judged their well-rested selves as more attractive. Correspondingly, this approach was more effective than a standard information program in promoting sleep hygiene, with benefits sustained for 1 month after the intervention.

Although these results are promising, the appearance-based intervention did not alter sleep duration itself. One possible explanation is that many paths lead to short sleep, of which a motivational component is only one. Thus, while appealing to attractiveness likely motivated change in presleep habits, it was not sufficient to alter sleep patterns. This account would suggest

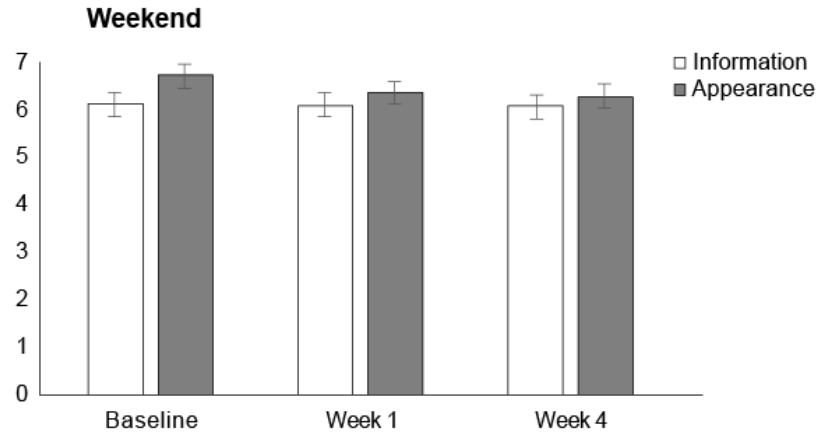

the need for a multipronged approach by public health agencies: for example, if sleep curtailment occurs because of immediate priorities such as pressing deadlines [16,17], an appearance-based intervention needs to be paired with techniques that help participants address their immediate priorities [44]. Alternatively, the intervention could be paired with structural changes such as a delayed school start time or reduced work hours, both of which have been found to increase sleep duration [45-47]. Further research will need to explore whether these pairings will ultimately address short sleep and how exactly motivation plays a role.

More broadly, our findings add to the growing body of research showing how an emphasis on appearances-though not sufficient as a stand-alone-may supplement traditional education in public health [25,26,28]. In recent years, appearance-based interventions have gained traction through the technological advances of photo-transformation software. These have been implemented in mobile- and Web-based 
applications [27,48,49] and have been applied across a range of health domains (sun protection [25], smoking cessation [26], nutrition [28], and-with this study-sleep). Given the potential reach of internet dissemination, one way forward may be to create a single appearance-based intervention that targets multiple health domains. If introduced in a timely manner (eg, incorporated into photo uploading features on a mobile dating application), this could boost existing public health campaigns, motivating healthy behaviors in a cost-effective manner.

\section{Study Limitations}

In presenting our study, we note several limitations in participant selection and randomization. First, we targeted participants with habitual short sleep, departing from earlier sleep education studies where participants were recruited regardless of sleep history [11]. Accordingly, we could not assess how the appearance-based intervention would affect the broader population. Second, we recruited university students, a group whose schedules are driven by high-stake deadlines within a short 13-week semester. It remains possible that stronger treatment effects would be observed in groups without similar deadlines (eg, adolescents or young working adults). Third, in choosing university students, we sought-in a proof-of-concept trial-to maximize the potential impact of our intervention. Across adulthood, although the likelihood of being a short sleeper is fairly even across age groups [50], concerns about physical appearances peak in young adults ( $\leq 24$ years) and decrease linearly across the life span [51]. We thus reasoned that the selected age group (18-24 years) would be most amenable to an appearance-based intervention. However, in choosing these age cutoffs, we did not assess directly whether participants valued their appearances and recognize that our findings may not generalize to other age groups-for example, to older participants whose appearances may be affected by normal aging. Moving forward, selection of the appearance-based strategy can thus be customized based on the importance of physical attractiveness to the individual. Finally, as an eHealth trial, we were unable to blind the identity of which intervention participants were randomized to.

\section{Conclusions}

In conclusion, we designed in this study a novel intervention emphasizing physical attractiveness as a function of sleep patterns. This was assessed through a rigorous randomized controlled trial design with the following [52]: (1) the key intervention personalized (following best practices in appearance-based interventions [28]), (2) sleep duration objectively assessed (via actigraphy), and (3) participants monitored for 5 weeks. Using this design, we found that the appearance-based intervention was more effective than standard education in promoting sleep hygiene, a precursor for healthier sleep. At the same time, these effects did not translate to sleep extension, suggesting the need to assess how appearance-based strategies can be paired with other interventions. In summary, while urging further replication and extension of this work, our preliminary results suggest that beauty - the driving force that launched a thousand ships-may have an adjunctive role in promoting sleep.

\section{Acknowledgments}

This work was supported by grants awarded to JCJL by the Singapore Ministry of Education (start-up grant number: R-607-264-057-121 and AcRF Tier 1: IG15-B052). The authors gratefully acknowledge Benjamin Low, Pramesh S/O Prabakaran, Eveline Tan, Cheslie dela Cruz, Jim Seet, and Roger Liew for assistance with study preparation, data collection, and data entry.

\section{Authors' Contributions}

IP and SNT participated in research design, data collection, and the writing of the paper. KMV participated in research design, data collection, data analysis, and the writing of the paper. MWLC, DIP, and JCJL participated in research design, data analysis, and the writing of the paper.

\section{Conflicts of Interest}

None declared.

\section{Multimedia Appendix 1}

Informed consent documentation.

[PDF File (Adobe PDF File)132 KB-Multimedia Appendix 1]

\section{Multimedia Appendix 2}

Tables S1-3: Additional analyses.

[PDF File (Adobe PDF File)22 KB-Multimedia Appendix 2]

\section{Multimedia Appendix 3}

CONSORT-eHEALTH checklist (V 1.6.1).

[PDF File (Adobe PDF File)2368 KB-Multimedia Appendix 3]

\section{References}


1. Patel SR, Hu FB. Short sleep duration and weight gain: a systematic review. Obesity (Silver Spring) 2008 Mar;16(3):643-653 [FREE Full text] [doi: 10.1038/oby.2007.118] [Medline: 18239586]

2. Chen X, Beydoun MA, Wang Y. Is sleep duration associated with childhood obesity? A systematic review and meta-analysis. Obesity (Silver Spring) 2008 Feb;16(2):265-274 [FREE Full text] [doi: 10.1038/oby.2007.63] [Medline: 18239632]

3. Fatima Y, Doi SA, Mamun AA. Longitudinal impact of sleep on overweight and obesity in children and adolescents: a systematic review and bias-adjusted meta-analysis. Obes Rev 2015 Feb;16(2):137-149. [doi: 10.1111/obr.12245] [Medline: 25589359]

4. Cappuccio FP, Cooper D, D'Elia L, Strazzullo P, Miller MA. Sleep duration predicts cardiovascular outcomes: a systematic review and meta-analysis of prospective studies. Eur Heart J 2011 Jun;32(12):1484-1492. [doi: 10.1093/eurheartj/ehr007] [Medline: 21300732]

5. Cappuccio FP, D'Elia L, Strazzullo P, Miller MA. Sleep duration and all-cause mortality: a systematic review and meta-analysis of prospective studies. Sleep 2010 May;33(5):585-592 [FREE Full text] [doi: 10.1093/sleep/33.5.585] [Medline: 20469800]

6. Gallicchio L, Kalesan B. Sleep duration and mortality: a systematic review and meta-analysis. J Sleep Res 2009 Jun;18(2):148-158 [FREE Full text] [doi: 10.1111/j.1365-2869.2008.00732.x] [Medline: 19645960 ]

7. Liu Y, Wheaton AG, Chapman DP, Cunningham TJ, Lu H, Croft JB. Prevalence of healthy sleep duration among adults--United States, 2014. MMWR Morb Mortal Wkly Rep 2016 Feb 19;65(6):137-141 [FREE Full text] [doi: 10.15585/mmwr.mm6506a1] [Medline: 26890214]

8. Consensus Conference Panel, Watson NF, Badr MS, Belenky G, Bliwise DL, Buxton OM, Non-Participating Observers, American Academy of Sleep Medicine Staff, et al. Recommended amount of sleep for a healthy adult: a joint consensus statement of the American Academy of Sleep Medicine and Sleep Research Society. J Clin Sleep Med 2015 Jun 15;11(6):591-592 [FREE Full text] [doi: 10.5664/jcsm.4758] [Medline: 25979105]

9. Healthy People 2020. SH-4: Increase the Proportion of Adults Who Get Sufficient Sleep URL: https://www.healthypeople.gov/ node/5261/data details [accessed 2018-10-13] [WebCite Cache ID 738paPcWv]

10. Irish LA, Kline CE, Gunn HE, Buysse DJ, Hall MH. The role of sleep hygiene in promoting public health: a review of empirical evidence. Sleep Med Rev 2015 Aug;22:23-36 [FREE Full text] [doi: 10.1016/j.smrv.2014.10.001] [Medline: 25454674]

11. Blunden SL, Chapman J, Rigney GA. Are sleep education programs successful? The case for improved and consistent research efforts. Sleep Med Rev 2012 Aug;16(4):355-370. [doi: 10.1016/j.smrv.2011.08.002] [Medline: 22104441]

12. Cassoff J, Knäuper B, Michaelsen S, Gruber R. School-based sleep promotion programs: effectiveness, feasibility and insights for future research. Sleep Med Rev 2013 Jun;17(3):207-214. [doi: 10.1016/j.smrv.2012.07.001] [Medline: 23063417]

13. Chung KF, Chan MS, Lam YY, Lai CS, Yeung WF. School-based sleep education programs for short sleep duration in adolescents: a systematic review and meta-analysis. J Sch Health 2017 Jun;87(6):401-408. [doi: 10.1111/josh.12509] [Medline: 28463450]

14. Bakotić M, Radosević-Vidacek B, Kosćec A. Educating adolescents about healthy sleep: experimental study of effectiveness of educational leaflet. Croat Med J 2009 Apr;50(2):174-181 [FREE Full text] [doi: 10.3325/cmj.2009.50.174] [Medline: 19399951]

15. Wolfson AR, Harkins E, Johnson M, Marco C. Effects of the Young Adolescent Sleep Smart Program on sleep hygiene practices, sleep health efficacy, and behavioral well-being. Sleep Health 2015 Sep;1(3):197-204 [FREE Full text] [doi: 10.1016/j.sleh.2015.07.002] [Medline: 29073440]

16. Orzech KM. A qualitative exploration of adolescent perceptions of healthy sleep in Tucson, Arizona, USA. Soc Sci Med 2013 Feb;79:109-116. [doi: 10.1016/j.socscimed.2012.05.001] [Medline: 22694989]

17. Suen LK, Hon KL, Tam WW. Association between sleep behavior and sleep-related factors among university students in Hong Kong. Chronobiol Int 2008 Sep;25(5):760-775. [doi: 10.1080/07420520802397186] [Medline: 18780202]

18. Kirby KN, Herrnstein RJ. Preference reversals due to myopic discounting of delayed reward. Psychol Sci 2016 May 6;6(2):83-89. [doi: 10.1111/j.1467-9280.1995.tb00311.x]

19. Green L, Myerson J. A discounting framework for choice with delayed and probabilistic rewards. Psychol Bull 2004 Sep;130(5):769-792 [FREE Full text] [doi: 10.1037/0033-2909.130.5.769] [Medline: 15367080]

20. Aggarwal S, Dizon-Ross R, Zucker A. Faculty Directory | The University of Chicago Booth School of Business. 2019. Incentivizing Behavioral Change: The Role of Time Preferences URL: $\underline{\text { https://faculty.chicagobooth.edu/rebecca.dizon-ross/ }}$ research/papers/Incentive Design.pdf

21. Purnell JQ, Gernes R, Stein R, Sherraden MS, Knoblock-Hahn A. A systematic review of financial incentives for dietary behavior change. J Acad Nutr Diet 2014 Jul;114(7):1023-1035 [FREE Full text] [doi: 10.1016/j.jand.2014.03.011] [Medline: 24836967]

22. Gerend MA, Cullen M. Effects of message framing and temporal context on college student drinking behavior. J Exp Soc Psychol 2008 Jul;44(4):1167-1173. [doi: 10.1016/j.jesp.2008.02.007]

23. de Bruijn GJ, Budding J. Temporal consequences, message framing, and consideration of future consequences: persuasion effects on adult fruit intake intention and resolve. J Health Commun 2016 Aug;21(8):944-953. [doi:

10.1080/10810730.2016.1179366] [Medline: 27442225] 
24. Langlois JH, Kalakanis L, Rubenstein AJ, Larson A, Hallam M, Smoot M. Maxims or myths of beauty? A meta-analytic and theoretical review. Psychol Bull 2000 May;126(3):390-423. [doi: 10.1037//0033-2909.126.3.390] [Medline: 10825783]

25. Williams AL, Grogan S, Clark-Carter D, Buckley E. Appearance-based interventions to reduce ultraviolet exposure and/or increase sun protection intentions and behaviours: a systematic review and meta-analyses. Br J Health Psychol 2013 Feb;18(1):182-217. [doi: 10.1111/j.2044-8287.2012.02089.x] [Medline: 22989352]

26. Flett K, Clark-Carter D, Grogan S, Davey R. How effective are physical appearance interventions in changing smoking perceptions, attitudes and behaviours? A systematic review. Tob Control 2013 Mar;22(2):74-79. [doi: 10.1136/tobaccocontrol-2011-050236] [Medline: 22573734]

27. Burford O, Jiwa M, Carter O, Parsons R, Hendrie D. Internet-based photoaging within Australian pharmacies to promote smoking cessation: randomized controlled trial. J Med Internet Res 2013 Mar 26;15(3):e64 [FREE Full text] [doi: 10.2196/jmir.2337] [Medline: 23531984]

28. Whitehead RD, Ozakinci G, Perrett DI. A randomized controlled trial of an appearance-based dietary intervention. Health Psychol 2014 Jan;33(1):99-102. [doi: 10.1037/a0032322] [Medline: 23527517]

29. Axelsson J, Sundelin T, Ingre M, van Someren EJ, Olsson A, Lekander M. Beauty sleep: experimental study on the perceived health and attractiveness of sleep deprived people. Br Med J 2010 Dec 14;341:c6614 [FREE Full text] [doi: 10.1136/bmj.c6614] [Medline: 21156746]

30. Sundelin T, Lekander M, Kecklund G, van Someren EJ, Olsson A, Axelsson J. Cues of fatigue: effects of sleep deprivation on facial appearance. Sleep 2013 Sep 1;36(9):1355-1360 [FREE Full text] [doi: 10.5665/sleep.2964] [Medline: 23997369]

31. Sundelin T, Lekander M, Sorjonen K, Axelsson J. Negative effects of restricted sleep on facial appearance and social appeal. R Soc Open Sci 2017 May;4(5):160918 [FREE Full text] [doi: 10.1098/rsos.160918] [Medline: 28572989]

32. Kim MA, Kim EJ, Kang BY, Lee HK. The effects of sleep deprivation on the biophysical properties of facial skin. J Cosmet Dermatol Sci Appl 2017;7(1):34-47. [doi: 10.4236/jcdsa.2017.71004]

33. Talamas SN, Mavor KI, Axelsson J, Sundelin T, Perrett DI. Eyelid-openness and mouth curvature influence perceived intelligence beyond attractiveness. J Exp Psychol Gen 2016 May;145(5):603-620. [doi: 10.1037/xge0000152] [Medline: 26913618]

34. Brown FC, Buboltz WJ, Soper B. Development and evaluation of the sleep treatment and education program for students (STEPS). J Am Coll Health 2006;54(4):231-237. [doi: 10.3200/JACH.54.4.231-237] [Medline: 16450848]

35. Carney CE, Buysse DJ, Ancoli-Israel S, Edinger JD, Krystal AD, Lichstein KL, et al. The consensus sleep diary: standardizing prospective sleep self-monitoring. Sleep 2012 Feb 1;35(2):287-302 [FREE Full text] [doi: 10.5665/sleep.1642] [Medline: 22294820]

36. Gellis LA, Lichstein KL. Sleep hygiene practices of good and poor sleepers in the United States: an internet-based study. Behav Ther 2009 Mar;40(1):1-9. [doi: 10.1016/j.beth.2008.02.001] [Medline: 19187812]

37. Morin CM, Vallières A, Ivers H. Dysfunctional beliefs and attitudes about sleep (DBAS): validation of a brief version (DBAS-16). Sleep 2007 Nov;30(11):1547-1554 [FREE Full text] [doi: 10.1093/sleep/30.11.1547] [Medline: 18041487]

38. Buysse DJ, Reynolds CF, Monk TH, Berman SR, Kupfer DJ. The Pittsburgh Sleep Quality Index: a new instrument for psychiatric practice and research. Psychiatry Res 1989 May;28(2):193-213. [doi: 10.1016/0165-1781(89)90047-4] [Medline: 2748771]

39. National Heart, Lung, and Blood Institute (NHLBI). 2011. In Brief: Your Guide to Healthy Sleep URL: http://www. nhlbi.nih.gov/files/docs/public/sleep/healthysleepfs.pdf [accessed 2015-08-01] [WebCite Cache ID 738q8K9P6]

40. Health Promotion Board, Singapore. 2015. Corporate Website URL: http://www.hpb.gov.sg/HOPPortal/content/conn/ HOPUCM/path/ContributionFolders/uploadedFiles/HPB Online/Educational Materials/sleep.pdf

41. Tiddeman BP, Burt DM, Perrett DI. Prototyping and transforming facial textures for perception research. IEEE Comput Graph Appl 2001;21(5):42-50. [doi: 10.1109/38.946630]

42. Kahan BC, Jairath V, Doré CJ, Morris TP. The risks and rewards of covariate adjustment in randomized trials: an assessment of 12 outcomes from 8 studies. Trials 2014 Apr 23;15:139 [FREE Full text] [doi: 10.1186/1745-6215-15-139] [Medline: 24755011]

43. Wittmann M, Dinich J, Merrow M, Roenneberg T. Social jetlag: misalignment of biological and social time. Chronobiol Int 2006;23(1-2):497-509. [doi: 10.1080/07420520500545979] [Medline: 16687322]

44. Ariely D, Wertenbroch K. Procrastination, deadlines, and performance: self-control by precommitment. Psychol Sci 2002 May;13(3):219-224. [doi: 10.1111/1467-9280.00441] [Medline: 12009041]

45. Wheaton AG, Chapman DP, Croft JB. School start times, sleep, behavioral, health, and academic outcomes: a review of the literature. J Sch Health 2016 May;86(5):363-381 [FREE Full text] [doi: 10.1111/josh.12388] [Medline: 27040474]

46. Schiller H, Lekander M, Rajaleid K, Hellgren C, Åkerstedt T, Barck-Holst P, et al. The impact of reduced worktime on sleep and perceived stress - a group randomized intervention study using diary data. Scand J Work Environ Health 2017 Mar 1;43(2):109-116 [FREE Full text] [doi: 10.5271/sjweh.3610] [Medline: 27942734]

47. Lockley SW, Cronin JW, Evans EE, Cade BE, Lee CJ, Landrigan CP, Harvard Work Hours, Health and Safety Group. Effect of reducing interns' weekly work hours on sleep and attentional failures. N Engl J Med 2004 Oct 28;351(18):1829-1837. [doi: 10.1056/NEJMoa041404] [Medline: 15509816] 
48. Brinker TJ, Seeger W. Photoaging mobile apps: a novel opportunity for smoking cessation? J Med Internet Res 2015 Jul 27;17(7):e186 [FREE Full text] [doi: 10.2196/jmir.4792] [Medline: 26215210]

49. Brinker TJ, Seeger W, Buslaff F. Photoaging mobile apps in school-based tobacco prevention: the mirroring approach. J Med Internet Res 2016 Jun 28;18(6):e183 [FREE Full text] [doi: 10.2196/jmir.6016] [Medline: 27352819]

50. Knutson KL, van Cauter E, Rathouz PJ, DeLeire T, Lauderdale DS. Trends in the prevalence of short sleepers in the USA: 1975-2006. Sleep 2010 Jan;33(1):37-45 [FREE Full text] [doi: 10.1093/sleep/33.1.37] [Medline: 20120619]

51. Pliner P, Chaiken S, Flett GL. Gender differences in concern with body weight and physical appearance over the life span. Pers Soc Psychol Bull 2016 Jul 2;16(2):263-273. [doi: 10.1177/0146167290162007]

52. Schulz KF, Altman DG, Moher D, CONSORT Group. CONSORT 2010 statement: updated guidelines for reporting parallel group randomised trials. Br Med J 2010 Mar 23;340:c332 [FREE Full text] [doi: 10.1136/bmj.c332] [Medline: 20332509]

\title{
Abbreviations \\ DBAS-16: Dysfunctional Beliefs and Attitudes about Sleep scale \\ PSQI: Pittsburgh Sleep Quality Index
}

\author{
Edited by G Eysenbach; submitted 14.10.18; peer-reviewed by I Mircheva, K Miller, V Rocio; comments to author 04.04.19; revised \\ version received 28.06.19; accepted 23.07.19; published 26.09.19 \\ Please cite as: \\ Perucho I, Vijayakumar KM, Talamas SN, Chee MWL, Perrett DI, Liu JCJ \\ A Web-Based Photo-Alteration Intervention to Promote Sleep: Randomized Controlled Trial \\ J Med Internet Res 2019;21(9):e12500 \\ URL: https://www.jmir.org/2019/9/e12500 \\ doi: $\underline{10.2196 / 12500}$ \\ PMID: $\underline{31573913}$
}

CIsabel Perucho, Kamalakannan M Vijayakumar, Sean N Talamas, Michael Wei-Liang Chee, David I Perrett, Jean C J Liu. Originally published in the Journal of Medical Internet Research (http://www.jmir.org), 26.09.2019 This is an open-access article distributed under the terms of the Creative Commons Attribution License (https://creativecommons.org/licenses/by/4.0/), which permits unrestricted use, distribution, and reproduction in any medium, provided the original work, first published in the Journal of Medical Internet Research, is properly cited. The complete bibliographic information, a link to the original publication on http://www.jmir.org/, as well as this copyright and license information must be included. 